\title{
Laser Induced Plasma Spectroscopy for the \\ Characterization of Aerosols and Particulates ${ }^{\dagger}$
}

\author{
Benjamin W. Smith, David W. Hahn*, Emily Gibb, \\ Igor Gornushkin and James D. Winefordner** \\ Departments of Chemistry and Mechanical Engineering* \\ Engineering Research Center for Particle Science and \\ Technology
}

\begin{abstract}
Laser induced plasma spectroscopy is beginning to find useful applications in the real time in situ detection of particulates and aerosols suspended in gases. Although the technique is almost 40 years old, it has become increasingly practical for this application during the last decade due to the development of more reliable lasers and optical detection systems, an improved understanding of the physical processes involved, and new data collection and analysis strategies. There is a pressing need for such detection techniques for industrial process and atmospheric monitoring. In this review, we examine literature concerned with the process of optical breakdown by focused lasers in gases, the role of particles in this process, and the characterization of particles using laser induced plasmas.
\end{abstract}

\section{Introduction}

Laser induced plasma spectroscopy (LIPS) or laser induced breakdown spectroscopy (LIBS) continues to receive wide attention for rapid, in situ chemical analysis of many different kinds of samples. (In this review, we use the acronyms interchangeably.) When a pulsed, high power laser is focused on any gas, liquid or solid, a bright, luminous plasma results, accompanied by a sharp acoustic shock wave. In simplistic terms, LIPS uses the emission spectrum of this plasma to obtain chemical composition information about the vaporized material. The vaporized sample is almost completely dissociated into free atoms and ions leading to a spectrum which is rich in elemental atomic and ionic lines. The technique, which dates to the early 1960 's, ${ }^{1}$ has enjoyed a revival during the last decade due to the development of array detectors and ever more reliable and rugged pulsed laser systems. It has found many applications in the direct, in situ analysis of solid, ${ }^{2,3}$ and gaseous materials. ${ }^{4}$ Telgheder and Khvostikov have reviewed most of the methods which are used to determine metal contaminants in

\footnotetext{
* University of Florida, Gainesville, FL 32611

${ }^{* *}$ Corresponding Author

+ Accepted: August 17, 2001
}

gases. ${ }^{5}$ In this review, we examine the specific application of LIPS to the chemical characterization of liquid and solid particles suspended in gases.

Laser induced plasma formation in gases has been the subject of continuous study ever since the first demonstration of optical breakdown by Maker et al., ${ }^{6}$ Meyerand and Haught ${ }^{7}$ and Damon and Romlinson ${ }^{8}$. The process is quite complex and sensitive to many experimental parameters such as laser intensity, wavelength and pulse characteristics, and gas composition and pressure. Subtle differences in laser temporal and spatial character are important and therefore, only fair agreement among different experimental measurements of breakdown thresholds has been possible. By 1965, Wright, ${ }^{9}$ Browne $^{10}$ and others had formulated the essentials of the breakdown mechanism and by the mid-1970's the basic features of laser breakdown in gases were well understood. Two excellent reviews from that period ${ }^{11,12}$ and the book by Raizer $^{13}$ summarize the mechanism of plasma formation and development. Here, we will restrict our discussion primarily to breakdown in air by lasers with $\approx 10$ ns pulse durations, which are most commonly used for spectrochemical analysis.

The process of laser plasma formation in gases is commonly considered in three phases, the initial ionization and breakdown, the continued interaction of 
the developing plasma with the remainder of the laser pulse, and, finally the propagation of the shock wave with the accompanying plasma decay. ${ }^{9}$ The initiation of plasma formation requires the presence of seed electrons. In rare instances, the natural background level of charge pairs, due to cosmic rays and radioactivity, may suffice, although the probability of such a charge pair being present in the small focal volume of a 10 ns laser pulse is extremely low. ${ }^{14}$ It is far more probable that the seed electron will be produced through multiphoton ionization of either $\mathrm{O}_{2}$ or $\mathrm{N}_{2}$ by the pulsed laser. For breakdown in air, this is an 8 or 10-photon process at $1064 \mathrm{~nm}$ (for $\mathrm{O}_{2}$ and $\mathrm{N}_{2}$, respectively) and approaches a 2-photon process in the UV. The threshold for breakdown, which can be defined as the minimum irradiance necessary to cause the formation of a visible spark, is therefore expected to be wavelength dependent, requiring less irradiance to cause breakdown at shorter wavelengths. A rough estimate of the spatially uniform and temporally constant photon flux, $\mathrm{F}_{\mathrm{TH}}$, (photons $/ \mathrm{s}-\mathrm{cm}^{2}$ ) needed to cause breakdown in a gas via multiphoton ionization has been given by Grey Morgan: ${ }^{8}$

$$
F_{T H} \approx \frac{\nu}{\sigma}\left(\frac{\delta k !}{\tau \nu}\right)^{1 / k}
$$

where $v$ is the laser frequency, $\sigma$ is the cross-section for absorption of a single photon, $\delta$ is the ionization fraction needed for breakdown to occur, $\mathrm{k}$ is the number of photon absorptions required to reach ionization, and $\tau$ is the laser pulse duration. This assumes that the lifetime of each virtual state is $1 / v$, photon arrival follows a Poisson distribution and $\mathrm{F}_{\mathrm{TH}} \sigma / v$ $<<1$. For the fundamental output of a $\mathrm{Nd}$ :YAG laser $(1064 \mathrm{~nm})$ in air, $\mathrm{k} \approx 10, \tau \approx 10^{-8} \mathrm{~s}, \sigma \approx 10^{-16} \mathrm{~cm}^{2}$, and $\left\langle v \approx 2.8 \times 10^{14} \mathrm{~s}^{-1}\right.$. If we take $\delta \approx 10^{-3}$, the breakdown threshold is $\approx 1.4 \times 10^{30}$ photons $/ \mathrm{s} \mathrm{cm}^{2}$, or about $300 \mathrm{GW} / \mathrm{cm}^{2}$. For a UV laser $(266 \mathrm{~nm}), v$ $=1.13 \times 10^{15} \mathrm{~s}^{-1}, \mathrm{k} \approx 3$ and the calculated breakdown threshold is $\approx 7 \mathrm{GW} / \mathrm{cm}^{2}$. These values are in reasonable agreement with experimental observations. In fact, experimental measurements vary widely because of the uncontrolled yet important influence of particles, which typically lower the threshold for breakdown by about 100 times. ${ }^{15}$ The presence of particles in the breakdown region causes the observed breakdown threshold to be dependent upon the size of the laser focus, there being a higher probability that the laser will encounter a random particle with increasing focus spot diameter. In clean air, reported breakdown thresholds for $10 \mathrm{~ns}$ pulse duration $1064 \mathrm{~nm}$ lasers range from $90-1600 \mathrm{GW} / \mathrm{cm}^{2}$. At $266 \mathrm{~nm}$, literature values range from $30-380 \mathrm{GW} / \mathrm{cm}^{2}$. At wavelengths much longer than the fundamental of the $\mathrm{Nd}$ :YAG laser (e.g., the $\mathrm{CO}_{2}$ laser at $10.6 \mu \mathrm{m}$ ), the photon energy, and thus the probability of multiphoton ionization, is so small that other sources of seed electrons are invariably required. ${ }^{16}$

Once breakdown is initiated, the plasma rapidly develops through an avalanche process caused by increasing inverse bremsstrahlung absorption (freefree absorption), i.e., the absorption of a photon by a free electron with collisional energy transfer to a gas molecule. When the electrons gain enough energy from this process, the gas is ionized and the electron concentration increases exponentially. The increased absorption of laser energy rapidly increases the temperature of the developing plasma and by the time the laser pulse terminates, an energetic, dense, highly ionized, rapidly expanding plasma has been formed. The development and decay of this plasma can be followed spectroscopically. The emission spectrum at early times is predominately a continuum which gradually evolves into a conventional spectrum of atomic and ionic lines and molecular bands. Figure 1 shows a time resolved spectrum of a laser plasma formed in atmospheric pressure laboratory air by a focused $1064 \mathrm{~nm}$ Nd:YAG laser with an irradiance of 175 $\mathrm{GW} / \mathrm{cm}^{2}$. The spectrum has been well-studied and is dominated by molecular bands due to $\mathrm{N}_{2}$ and $\mathrm{N}_{2}{ }^{+}$and by the ionic lines of $\mathrm{N}^{+}, \mathrm{N}^{++}, \mathrm{O}^{+}$and $\mathrm{O}^{++} .17,18$ The luminous plasma ball expands as it cools, emitting detectable radiation for tens to hundreds of microseconds. The emitted radiation is subsequently collected, dispersed spectrally and recorded using a suitable

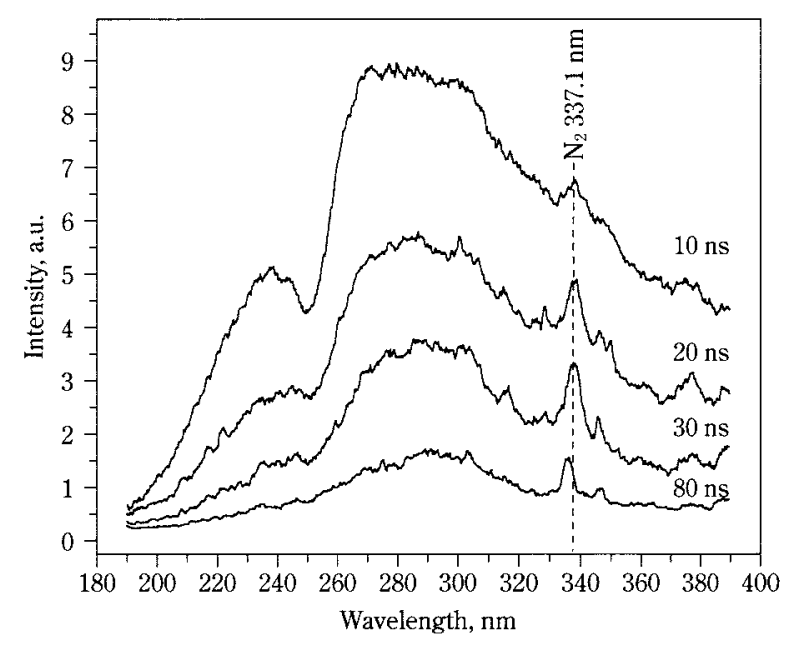

Fig. 1 Typical time-resolved laser induced plasma spectra in air at four delay times. 
PQetactor, commonly a charge-coupled device (CCD) or photodiode array. A typical LIPS schematic is shown in Figure 2, in which the primary focusing lens also collects the plasma emission. Fiber optic coupling of the plasma emission to the spectrometer is useful for many industrial and field applications. Typical measured values for the plasma temperature, at the peak of radiant intensity, range from $10,000-$ $20,000 \mathrm{~K}$ and the plasma typically expands to a volume of several cubic mm. Villermaux et al. made a careful study of the spectroscopic and chemical behavior of plasmas formed by a Nd:YAG laser in various gases $\left(\mathrm{N}_{2}, \mathrm{CO}_{2}, \mathrm{O}_{2}, \mathrm{Ar}, \mathrm{H}_{2}\right.$ and $\mathrm{He}$ ) from $100-760$ torr. ${ }^{19}$ They were able to isolate three effects relating to the plasma emission: the bremsstrahlung, atomic and molecular spectral lines and a late peak during the supersonic shock wave in the direction of the laser. They did not observe any multiphoton absorption or macroscopic chemical reactions below the breakdown threshold. In a more recent study, Simeonsson and Miziolek reported on the spectroscopy of plasmas formed in air, $\mathrm{CO}$ and $\mathrm{CO}_{2}$ using lasers at 193, 266, 355, 532 and $1064 \mathrm{~nm} .{ }^{20}$ They measured breakdown thresholds which ranged from $7.3 \mathrm{GW} / \mathrm{cm}^{2}$ at $193 \mathrm{~nm}$ in $\mathrm{CO}$ to $300 \mathrm{GW} / \mathrm{cm}^{2}$ at $355 \mathrm{~nm}$ in CO. In air, the threshold was lowest at $193 \mathrm{~nm}\left(9.7 \mathrm{GW} / \mathrm{cm}^{2}\right)$, highest at $355 \mathrm{~nm}(270$ $\mathrm{GW} / \mathrm{cm}^{2}$ ) and declined to $200 \mathrm{GW} / \mathrm{cm}^{2}$ at $1064 \mathrm{~nm}$. They also reported time-resolved plasma electron densities $\left(2 \times 10^{17}-2 \times 10^{18} \mathrm{~cm}^{-3}\right)$, ionization temperatures $(16,000-23,000 \mathrm{~K})$ and excitation temperatures $(11,000-22,000 \mathrm{~K})$ for the various gas/wavelength combinations.

The physics of the laser breakdown process is greatly changed if particles happen to be present in the focal region. ${ }^{21}$ Absorption of the laser light can now take place on the particle surface. Haught and

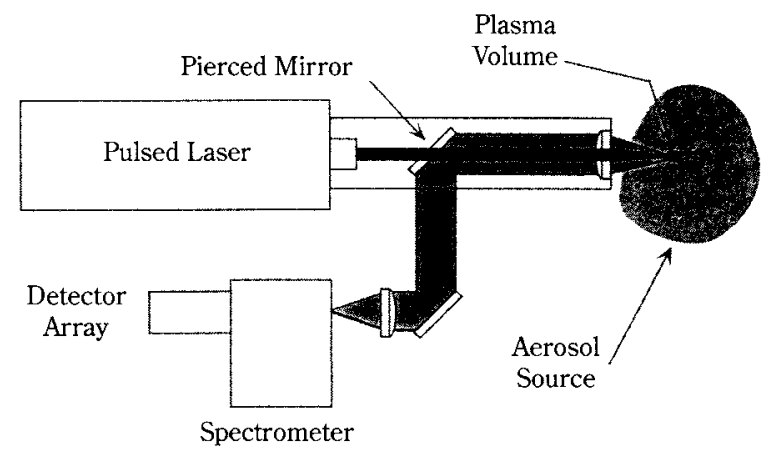

Fig. 2 Schematic diagram of a typical LIPS experiment for studying particles in a gas stream.
Polk, ${ }^{22}$ in 1966, made one of the first observations of a laser induced plasma on a single particle. Using 10$20 \mu \mathrm{m}$ diameter electrostatically levitated lithium hydride $(\mathrm{LiH})$ particles and a ruby laser, they measured the total charge produced and demonstrated that the plasma was completely ionized, producing about $8.5 \times 10^{14}$ charge pairs from about $10^{14}$ molecules of LiH. They also showed that the charge density was essentially isotropic about the laser beam focal point. Throughout the 1970's, there was great interest in the interaction of intense laser beams with particles, especially because of the important role which aerosols play in determining the transport of laser radiation through the atmosphere and because of nuclear fusion research. If a particle is present in the focal volume of the laser during breakdown, it will be vaporized and contribute to the developing plasma. Moreover, the threshold for breakdown will be greatly reduced due to local heating on the particle surface, thermoelectric emission and resonance effects. For transparent aerosols, there are additional effects due to localized focusing of the laser beam by the particle. ${ }^{23}$ The relative importance of the various possible mechanisms involved in breakdown with particles depends on the particle size, refractive index and absorption at the laser wavelength. Reported breakdown thresholds for various particles (e.g., water, bromoform, pyridine, glycerol, carbon, $\mathrm{NaCl}$, ethanol, methanol, $\mathrm{CCl}_{4}$, ethylbromide, clay, aluminum, alumina, germanium, oleic acid, diesel fuel) of $\approx 10-150 \mu \mathrm{m}$ diameter for laser wavelengths from $0.266-10.6 \mu \mathrm{m}$, range from $0.04-4 \mathrm{GW} / \mathrm{cm}^{2}$ for lasers in the $10 \mathrm{~ns}$ pulse duration regime. ${ }^{24,25,26} \mathrm{Usu}-$ ally, larger particles tend to cause lower breakdown thresholds. However, other factors, such as refractive index, play important roles, making it difficult to generalize. Several studies have been reported showing that the breakdown threshold is independent of particle size. ${ }^{27,28}$ Aqueous aerosols do not reduce the breakdown threshold as much as solid aerosols. For long wavelength lasers (e.g., the $\mathrm{CO}_{2}$ laser at 10.6 $\mu \mathrm{m})$, breakdown is only possible in the presence of a particle, the photon energy being far too low to produce any seed electrons from multiphoton ionization. ${ }^{15,29}$ Smith has developed a theoretical model for calculating the breakdown threshold on particles and solid surfaces which provided good agreement with measurements over a wide range of pulse durations, wavelengths and particle sizes. ${ }^{30}$

From the viewpoint of using laser induced plasmas for characterization of particles and aerosols, the important considerations are that plasmas are rela- 
P fively easy to produce in particle-laden gases (with a variety of laser systems) and any particle smaller than about $10-20 \mu \mathrm{m}$ will be completely vaporized and incorporated into the plasma. Vaporization and subsequent excitation by the laser induced plasma forms the basis for chemical characterization of particles by emission spectroscopy.

\section{Applications to Particle Characterization}

The application of LIPS for chemical characterization of aerosols probably originated about 1978 with the suggestion by Belyaev et al. that such a technique would be ideal for remote, real time analysis. ${ }^{31}$ About the same time, Gavrilov and co-workers ${ }^{32}$ took the unique approach of using a $\mathrm{CO}_{2}$ laser with a special pulse shape such that the initial, brief portion of the pulse was above the breakdown threshold and the long tail of the pulse well below it. This produced efficient breakdown and particle vaporization while allowing the subsequent plasma to be formed with the optimum temperature for good signal/noise ratio in the emission spectrum. Loree and Radziemski reported on time-integrated and time-resolved LIBS detection of various particles in gas streams in a pair of papers published in $1981 .^{33,34}$ In the first paper, ${ }^{32}$ using time-integrated measurements and a $\mathrm{Nd}$ :YAG laser $\left(1064 \mathrm{~nm}, 10-100 \mathrm{MW} / \mathrm{cm}^{2}\right)$, they detected $\mathrm{Na}$ and $\mathrm{K}$ in a coal gasifier output, Be in air and $\mathrm{P}, \mathrm{S}$ and $\mathrm{Cl}$ from various volatile organic compounds. In the companion paper, ${ }^{33}$ they added time resolution using a gated optical multichannel analyzer or a gated photomultiplier tube. Here, they detected P (253 nm) and $\mathrm{Cl}(837.5 \mathrm{~nm})$ in air with estimated limits of detection of $15 \mathrm{ppm}$ and $60 \mathrm{ppm}(\mathrm{w} / \mathrm{w})$, respectively. Most of the essential aspects of the technique were presented by Radziemski et al. in 1983 in a study of the detection of Be particles in air. ${ }^{35,36}$ They measured temperature and electron densities in the air plasma and concluded that the plasma is in approximate local thermodynamic equilibrium at times longer than about 1 $\mu \mathrm{s}$. Using the unresolved Be II doublet at $313.1 \mathrm{~nm}$, they obtained a limit of detection of $0.7 \mu \mathrm{g} / \mathrm{m}^{3}$ for Be in air ( $0.6 \mathrm{ng} \mathrm{Be} / \mathrm{g}$ air). In field measurements at two coal gasifiers, they detected spectral features due to $\mathrm{Na}, \mathrm{K}, \mathrm{H}, \mathrm{O}, \mathrm{O}^{+}, \mathrm{C}, \mathrm{C}^{+}, \mathrm{C}^{2+}, \mathrm{Ca}, \mathrm{Ca}^{+}, \mathrm{Si}, \mathrm{Mg}, \mathrm{CN}, \mathrm{N}_{2}$, $\mathrm{CO}, \mathrm{O}_{2}$ and $\mathrm{S}$, demonstrating the potential for practical real-time particle monitoring. They also reported limits of detection for $\mathrm{Na}, \mathrm{P}, \mathrm{As}$ and $\mathrm{Hg}$ of $0.006,1.2$, 0.5 and $0.5 \mu \mathrm{g} / \mathrm{g}$ air, respectively. In a related work, Cremers and Radziemski also studied the detection of $\mathrm{Cl}$ and $\mathrm{F}$ in air using both vapor and particle sample introduction. ${ }^{37}$ They reported limits of detection for $\mathrm{Cl}$ and $\mathrm{F}$ of 8 and $38 \mathrm{ppm}(\mathrm{w} / \mathrm{w})$, respectively.

In 1984, Leslie, et al. used a $\mathrm{D}_{2}-\mathrm{F}_{2}$ laser with a $1 \mu \mathrm{s}$ pulse width at $3.58-4.78 \mu \mathrm{m}$ to study plasma formation in maritime liquid and solid aerosols. ${ }^{38}$ For pure aqueous aerosols and aerosols containing $\mathrm{NaCl}, \mathrm{SiO}_{2}$ and $\mathrm{Al}_{2} \mathrm{O}_{3}$, they observed a breakdown threshold which decreased from about $8 \times 10^{8} \mathrm{~W} / \mathrm{cm}^{2}$ for $1 \mu \mathrm{m}$ radius particles to $8 \times 10^{7} \mathrm{~W} / \mathrm{cm}^{2}$ for particles larger than about $10 \mu \mathrm{m}$. They also noted the characteristic propagation of the breakdown plasma in the direction of the incident laser beam, and demonstrated good agreement between their observations and a theoretical model.

Srchontaki and Crouch, in 1988, developed a single droplet sample introduction system for LIBS. ${ }^{39}$ They vaporized single droplets ranging from about $100-$ $160 \mu \mathrm{m}$ in diameter and found that the spectral line intensity decreased slightly with increasing droplet size. They reported good linearity (about 3 decades) for $\mathrm{Li}, \mathrm{Na}, \mathrm{Mg}, \mathrm{Ca}, \mathrm{Mn}$ and $\mathrm{Al}$ with detection limits ranging from $0.3-7 \mathrm{ppm}$. Radziemski et al. used a similar approach to study dry aerosols of $\mathrm{Cd}, \mathrm{Pb}$ and $\mathrm{Zn} .{ }^{40}$ Using an irradiance of $\approx 10^{10} \mathrm{~W} / \mathrm{cm}^{2}$ from a $\mathrm{Nd}$ YAG laser $(1064 \mathrm{~nm})$, they reported limits of detection of $0.02,0.2$ and $0.24 \mu \mathrm{g} / \mathrm{g}$ (of air) for these three elements with linear ranges of about two orders of magnitude. They suspected that the upper limit of linear response was determined by the inability of the laser to completely vaporize particles larger than about $10 \mu \mathrm{m}$, although no direct experimental evidence was reported. After these initial studies, applications of LIBS to particle characterization have been primarily directed at in-situ, real-time detection in industrial processes (e.g., relatively dense particle concentration systems). Although the potential exists for real-time atmospheric monitoring (e.g., very dilute particle concentrations, see Sneddon's review ${ }^{41}$ and Harith et $a l{ }^{42}$ ), this remains a research direction awaiting exploration.

The application of LIBS to industrial process monitoring is extremely attractive because there are very few techniques which can provide such real time, in situ measurements of elemental concentrations. The usual approach, collecting samples on filters followed by dissolution and elemental analysis in the laboratory, is time consuming and sacrifices all information regarding relationships between particle size and composition. One option, to preserve this information, is to use LIBS for rapid quantitative analysis of particulates collected on filters. Arnold and Cremers ${ }^{43}$ have reported on the determination of thalium on fil- 
Ptersin less than 1 minute with a limit of detection of $40 \mathrm{ng} / \mathrm{cm}^{2}$. While not a real-time measurement, this approach significantly shortens the analysis time for samples collected in this way. Panne et al. have used an automated approach where a continuous filter belt conveys the collected particulate to a portable LIBS instrument (Nd:YAG, $1064 \mathrm{~nm}, 30 \mathrm{~mJ} /$ pulse) for near on-line analysis in a municipal waste incinerator. ${ }^{44}$ They reported limits of detection ranging from $10-$ $500 \mathrm{ng} / \mathrm{cm}^{2}$ for Cd, Ni, As, Co, Mn, Sb, Cr, Tl, Sn, V, $\mathrm{Cu}$ and $\mathrm{Pb}$. For their sampling system, these corresponded to $0.03-1.3 \mu \mathrm{g} / \mathrm{m}^{3}$ in the stack gas. The first application of LIBS to a combustion environment for real-time, in situ measurements appeared in 1989 when Ottesen et al. reported on a hybrid technique which also provided information on particle size and velocity. ${ }^{45}$ They used two continuous wave lasers (He$\mathrm{Ne}$ at $633 \mathrm{~nm}$ and Ar-ion at $488 \mathrm{~nm}$ ) for light scattering and velocimetry measurements simultaneously with a frequency-doubled Nd:YAG (100 mJ, $532 \mathrm{~nm})$ for LIPS. They demonstrated simultaneous, semiquantitative detection of $\mathrm{Si}, \mathrm{C}, \mathrm{Fe}, \mathrm{Al}, \mathrm{Ca}, \mathrm{Ti}, \mathrm{Mg}, \mathrm{Ba}$, $\mathrm{Li}, \mathrm{Mn}$ and $\mathrm{Sr}$ in 30-75 $\mu \mathrm{m}$ diameter coal particles fed into a combustion reactor system. Measurements of bulk concentrations as well as on a particle by particle basis were presented. In a related work, Ottesen et al. demonstrated semi-quantitative determination of $\mathrm{Mg}, \mathrm{Ca}, \mathrm{Al}, \mathrm{Si}, \mathrm{Fe}$ and $\mathrm{Ti}$ in individual coal particles and made a particle-by-particle comparison with $\mathrm{SEM}^{46}$. There have been several studies of LIPS using bulk measurements in aqueous aerosols. Winefordner et al., examined the use of an ArF laser (193 nm) for LIPS in dense aerosols. ${ }^{47}$ They reported bulk concentration limits of detection ranging from $0.3-20$ ppm for $\mathrm{Li}, \mathrm{Na}, \mathrm{K}, \mathrm{Mg}, \mathrm{Ca}, \mathrm{Mn}, \mathrm{Sr}, \mathrm{Al}, \mathrm{Ga}$ and $\mathrm{In}$ using a simple pneumatic nebulization system probed by the focused laser. Alexander and Poulain made a thorough study of LIBS on a salt water aerosol using a $\mathrm{KrF}$ laser $(248 \mathrm{~nm})$ delivering about $50 \mathrm{GW} / \mathrm{cm}^{2}{ }^{48}$ They compared performance with mono- and polydisperse aerosols and reported on the spatial and temporal behavior of $\mathrm{Na}$ and $\mathrm{H}$ spectral lines. Using the ratio of the $\mathrm{Na} 589 \mathrm{~nm}$ emission to the $\mathrm{H} 656 \mathrm{~nm}$ emission as the analytical measure, they also obtained calibration curves as a function of particle size (23$90 \mu \mathrm{m}$ ) showing a somewhat higher sensitivity for larger particles. They reported a limit of detection of about $160 \mathrm{ppm}$ for $\mathrm{Na}$. Schechter has applied LIBS (Nd:YAG, $1064 \mathrm{~nm}$ ) to the determination of $\mathrm{Fe}, \mathrm{Ca}, \mathrm{Zn}$ and $\mathrm{Pb}$ in particulate streams from a steel processing facility. ${ }^{49} \mathrm{~A}$ unique software was used to manipulate the spectra on a single shot basis, allowing the rejec- tion of spectra which were irregular or had poor S/N. Typically about $75 \%$ of the recorded spectra were discarded. A detection limit of about $1 \%$ was reported for Zn. Peng and coworkers at Sandia National Laboratories made the first really thorough study involving continuous emissions monitoring in an industrial environment. ${ }^{50}$ They reported on the use of a LIBS instrument (Nd:YAG, $532 \mathrm{~nm}, 300 \mathrm{~mJ} /$ pulse) for the detection of 11 metals ( $\mathrm{Sb}, \mathrm{As}, \mathrm{Be}, \mathrm{Cd}, \mathrm{Ar}, \mathrm{Co}, \mathrm{Pb}, \mathrm{Hg}$, $\mathrm{Mn}, \mathrm{Ni}$ and $\mathrm{Se}$ ) in stack gas emissions. They calibrated the system with a pneumatic nebulizer which produced $3 \times 10^{5}$ particles $/ \mathrm{cm}^{3}$ and of $0.3-15 \mu \mathrm{m}$ diameter and demonstrated good accuracy in field measurements on a thermal waste treatment plant. Their limits of detection ranged from $0.1 \mu \mathrm{g} / \mathrm{m}^{3}$ for Be to $250 \mu \mathrm{g} / \mathrm{m}^{3}$ for $\mathrm{Pb}$. Yalcin et al., made a specific study of the influence of ambient and experimental conditions (variations in the background gas, the presence of particles, humidity and laser power) on the performance of LIPS for toxic metal monitoring. ${ }^{51}$ Their system used a Nd:YAG laser at $532 \mathrm{~nm}$ and test aerosols were produced with a pneumatic nebulizer and desolvation system. They measured plasma temperatures and electron number densities as a function of the parameters listed above and concluded that none of these factors had any significant influence.

In the first demonstration of LIBS in a harsh, turbulent, highly luminous combustion system, Yueh et al. used a Nd:YAG laser $(532 \mathrm{~nm}, 100 \mathrm{~mJ} /$ pulse, 130 $\mathrm{GW} / \mathrm{cm}^{2}$ ) to monitor $\mathrm{Ca}, \mathrm{Fe}, \mathrm{Al}, \mathrm{Ti}$ an $\mathrm{Sr}$ in a large magnetohydrodynamic coal-fired flow facility. ${ }^{52}$ They did not report limits of detection but only demonstrated the ability to detect these species in an operating combustion system. In a continuation of this work, another successful field demonstration involving measurements on the exhaust gas stream from a plasma torch waste treatment facility was reported by Singh et al. ${ }^{53}$ They used a similar Nd:YAG laser system $(532 \mathrm{~nm})$ and calibrated with nebulized aerosols. Using $50 \mathrm{~s}$ measurement times (500 laser shots), they reported limits of detection for $\mathrm{As}, \mathrm{Be}, \mathrm{Co}, \mathrm{Cr}, \mathrm{Zn}, \mathrm{Cd}$, $\mathrm{Hg}, \mathrm{Sb}, \mathrm{Sn}, \mathrm{Mn}, \mathrm{Ni}, \mathrm{Pb}$ and $\mathrm{Fe}$ ranging from $1-680$ $\mu \mathrm{g} / \mathrm{m}^{3}$ and obtained good correlation in field tests with reference methods (EPA Method 5 with a multiple metals sampling train). Figure 3 shows a typical spectrum containing numerous elemental lines.

Hahn et al. used a conditional data analysis approach to obtain particle size and composition using LIBS (Nd:YAG, $1064 \mathrm{~nm}, 300 \mathrm{~mJ}$ ) in dilute sample streams. ${ }^{54}$ In measurements on a $220 \mathrm{~kW}$ natural-gasfired pyrolytic waste processing unit burning municipal solid waste, they successfully measured $\mathrm{Cr}, \mathrm{Mn}$ 


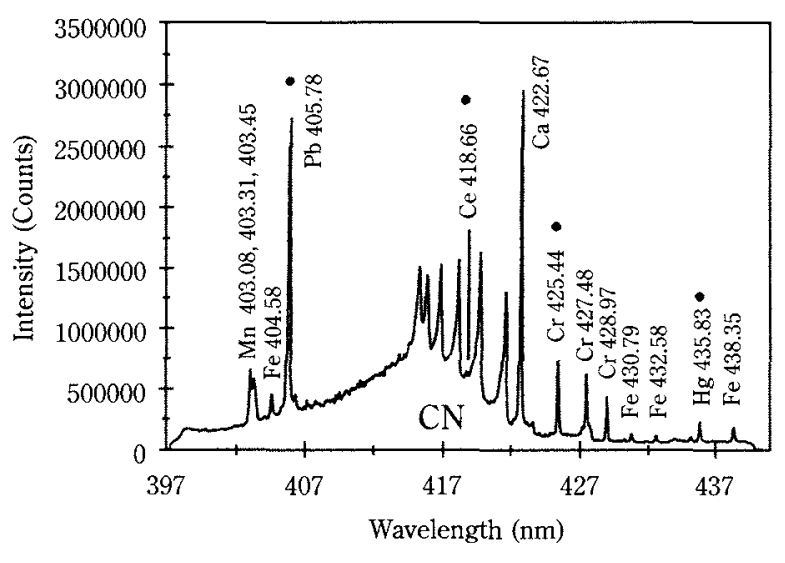

Fig. 3 Typical LIPS spectrum in an industrial effluent, taken from Ref. 50 , p. 250 , with permission.

and $\mathrm{Fe}$ in the exhaust gases and found good agreement with EPA Method 29. Their results demonstrated significant advantages of conditional data analysis of individual spectra compared to time-averaged data collection. In this approach, individual emission spectra were only retained if they contained emission features other than those found in the background gas. By taking into account the frequency with which these spectra occur, one obtains a calibration relationship with a greatly improved limit of detection. In an extension of this work, Hahn, extracted particle size information of individual particles using a calibration procedure based on known monodisperse polymer particles containing magnetite. ${ }^{55} \mathrm{He}$ also demonstrated the detection and sizing of individual magnesium-containing particles with an average diameter of about $300 \mathrm{~nm}$ in ambient air. Hahn and Lunden further explored single-particle analysis in a number of laboratory aerosol streams containing $\mathrm{Cr}, \mathrm{Mg}$, and $\mathrm{Ca}$ particles. ${ }^{56}$ Figure 4 shows a LIPS-based size distribution recorded for chromium particles at an overall mass concentration of $21 \mathrm{ng} / \mathrm{g}$ (ppb, mass basis).

Lemieux et al. reported the results of a major DOE/EPA sponsored field test of multimetal continuous emission monitoring technologies which took place in 1997 and included LIBS instrumentation. ${ }^{57}$ Tests were carried out in the EPA rotary kiln incinerator simulator using seven monitoring systems, two commercial and five prototypes. Elements included in the tests included $\mathrm{As}, \mathrm{Be}, \mathrm{Cr}, \mathrm{Cd}, \mathrm{Pb}$ and $\mathrm{Hg}$ ranging from $20-182 \mu \mathrm{g} / \mathrm{m}^{3}$. None of the systems evaluated were able to monitor all 6 test elements with the required relative accuracy of $20 \%$. The LIBS instruments yielded accuracies ranging from $19-367 \%$ and a spectral interference problem for $\mathrm{Cd}$ and As lines was reported. Panne et al. have developed a LIPS

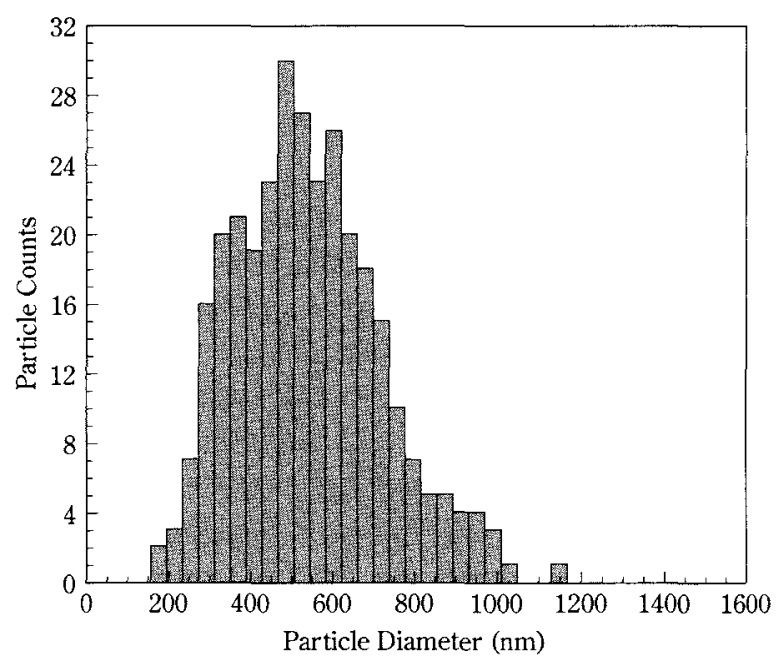

Fig. 4 A LIPS-based sized distribution for chromium particles.

system (Nd:YAG, $1064 \mathrm{~nm}, 200 \mathrm{~mJ} /$ pulse) optimized for the detection of $\mathrm{Cr}$ and evaluated it for rapid monitoring of optical emission from particulates at an electroplating facility. ${ }^{58}$ Using nebulized solutions for calibration, they obtained a linear response from particle densities between $14 \mu \mathrm{g} / \mathrm{m}^{3}$ and $5000 \mu \mathrm{g} / \mathrm{m}^{3}$. Good correlation was obtained against a reference method and continuous emission monitoring was demonstrated.

\section{Concluding Remarks}

Laser-induced plasma spectroscopy has reached the point in development where it will begin to find routine applications in industrial process monitoring. It has already been demonstrated that reliable detection of many elements of interest are readily detectable in the necessary concentration ranges. Rugged systems have been designed and proven in field tests. Recent work has established the ability of this technique for the quantitative analysis of individual aerosol particles. Further work is needed to find a reliable means for calibration in order to improve the accuracy. The use of this technique for continuous monitoring of dilute atmospheric aerosols (such as in routine atmospheric pollution monitoring) has yet to be developed but nevertheless appears promising in light of recent work with industrial emissions.

\section{Acknowledgements}

This work was supported by the Engineering Research Center (ERC) for Particle Science and Technology at the University of Florida, the National 
Bcience Foundation grant No. EEC-94-02989 and the Industrial Partners of the ERC.

\section{References Cited}

1) Brech, F: "Optical microemission stimulated by a ruby maser," Appl. Spectrosc., 16, 59 (1962).

2) Rusak, D. A., Castle, B. C., Smith, B. W. and Winefordner, J. D.: "Fundamentals and applications of laser-induced breakdown spectroscopy," Crit. Rev. Anal. Chem., 27, 257-290 (1997).

3) Laser-Induced Plasmas and Applications, Ed. L. J. Radziemski and D. A. Cremers, Marcel Dekker, Inc., New York (1989).

4) Martin, M. Z., Cheng, M-D and Martin, R. C.: “Aerosol measurement by laser-induced plasma technique: A Review," Aerosol Sci. Tech., 31, 409-421 (1999).

5) Telgheder, U. and Khvoltikov, V. A.: "Collection and determination of metal contaminants in gases," J. Anal. Atom. Spectrom., 12, 1-6 (1997).

6) Maker, P. D., Terhune, R. W. and Savage, C. M.: "Optical third harmonic generation in various solids and liquids," Proc. $3^{\text {rd }}$ Int. Conf. On Quantum Electronics, ed. P. Grivet and N. Bloembergen (New York: Columbia University Press), pp. 1559-1565 (1963).

7) Meyerand, R. G. and Haught, A. F.: "Gas breakdown at optical frequencies," Phys. Rev. Lett., 11, 401-403 (1963).

8) Damon, E. K. and Tomlinson, R. G.: "Observation of ionization of gases by a ruby laser," Appl. Opt., 2, 546547 (1963).

9) Wright, J. K. Wright: "Theory of the electrical breakdown of gases by intense pulses of light," Proc. Phys. Soc., 84, 41-46 (1964).

10) Browne, P. F.: "Mechanism of gas breakdown by lasers," Proc. Phys. Soc., 86 1323-1332 (1965).

11) Smith, D. C. and Meyerand, Jr., R. G.: "Laser Radiation Induced Gas Breakdown," in Principles of Laser Plasmas, Ed. G. Bekefi, Wiley-Interscience, New York, 1976.

12) Grey Morgan, C.: "Laser-induced breakdown of gases," Rep. Prog. Phys., 38, 621-665 (1975).

13) Raizer, Yu. P.: Laser-induced discharge phenomena, Consultants Bureau, New York, 1977.

14) Tozer, B. A.: "Theory of the ionization of gases by laser beams," Phys. Rev., 137, 1665-1667 (1965).

15) Lencioni, D. E. and Pettingill, L. C.: "The dynamics of air breakdown initiated by a particle in a laser beam," $J$. Appl. Phys., 48, 1848-1851 (1977).

16) Caressa, J-P, Autric, M., Dufresne, D. and Bournot, Ph.: "Experimental study of $\mathrm{CO}_{2}$-laser-induced air breakdown over long distances," J. Appl. Phys., 50, 6822-6825 (1979).

17) Armstrong, R. A., Lucht, R. A. and Rawlins, W. T.: "Spectroscopic investigation of laser-initiated low-pressure plasmas in atmospheric gases," Appl. Opt., 22, 15731577 (1983).

18) Nordstrom, R. J.: "Study of laser-induced plasma emission spectra of $\mathrm{N}_{2}, \mathrm{O}_{2}$, and ambient air in the region 350 nm to 950 nm," Appl. Spectrosc., 49, 1490-1499 (1995).

19) De Montgolfier, Ph., Dumont, P., Mille, Y. and Villermaux, J.: "Laser-induced gas breakdown: spectroscopic and chemical studies," J. Phys. Chem., 76, 31-37 (1972).

20) Simeonsson, J. B. and Miziolek, A. W.: "Spectroscopic studies of laser-produced plasmas formed in $\mathrm{CO}$ and $\mathrm{CO}_{2}$ using 193, 266, 355, 532 and $1064 \mathrm{~nm}$ laser radiation," Appl. Phys. B, 59, 1-9 (1994).

21) Lushnikov, A. A. and Negin, A. E.: "Aerosols in strong laser beams," J. Aerosol Sci., 24, 707-735 (1993).

22) Haught, A. F. and Polk, D. H.: "High-temperature plasmas produced by laser beam irradiation of single solid particles," Phys. Fluids, 9, 2047-2056 (1966).

23) Hsieh, W. F., Eickmans, J. H. and Chang, R. K.: "Internal and external laser-induced avalanche breakdown of single droplets in an argon atmosphere," J. Opt. Soc. Amer. $B, 4,1816-1820$ (1987).

24) Pinnick, R. G., Biswas, A., Armstrong, R. L., Gerard Jennings, S., Pendleton, J. D. and Fernadez, G.: "Micron-sized droplets irradiated with a pulsed $\mathrm{CO}_{2}$ laser: measurement of explosion and breakdown thresholds," Appl. Opt., 29, 918-925 (1990).

25) Pinnick, R. G., Biswas, A., Pendleton, J. D. and Armstrong, R. L.: "Aerosol-induced laser breakdown thresholds: effect of resonant particles," Appl. Opt., 31, 311-318 (1992).

26) Chylek, P., Jazembski, M. A., Chou, N. Y. and Pinnick, R. G.: "Effect of size and material of liquid spherical particles on laser-induced breakdown," Appl. Phys. Lett., 49, 1475-1477 (1986).

27) Smith, D. C. and Brown, R. T.: "Aerosol-induced breakdown with $\mathrm{CO}_{2}$ laser radiation," J. Appl. Phys., 46 11461154 (1975).

28) Mamonov, V. K.: "Air breakdown minimized by breakdown in aqueous aerosol drops acted upon by radiation with $\lambda=1.06 \mu \mathrm{m}$," Second All-Union Conference on Propagation of Laser Radiation in a Disperse Medium. Sum mary of Proceedings, Part II, pp. 249-251, English trans., Plenium Publishing Corp., New York (1984).

29) Bunkin, F. V. and Savranskii, V. V.: "Optical breakdown of gases induced by the thermal explosion of suspended macroscopic particles," Sov. Phys. -JETP, 38 1091-1096 (1974).

30) Smith, D. C.: "Gas breakdown initiated by laser radiation interaction with aerosols and solid surfaces," $J$. Appl. Phys., 48, 2217-2225 (1977).

31) Belyaev, E. B., Godlevskii, A. P. and Kopytin, Yu. D.: "Laser-spectroscopy analysis of aerosols," Quant. Elect., (Moscow), 5, 2594-2601 (1978).

32) Gavrilov, V. M, Golub, S. L. and Skripkin, A. M.: "Optimal conditions for laser elemental analysis of aerosols," Second All-Union Conference on Propagation of Laser Radiation in a Disperse Medium. Summary of Proceedings, Part II, pp. 265-268, English trans., Plenium Publishing Corp., New York (1984).

33) Loree, T. R. and Radziemski, L. J.: "Laser-induced breakdown spectroscopy: Time-integrated applications," Plasma Chem. Plasma Proc., 1, 271-279 (1981). 
34N Radziemski, L. J. and Loree, T. R.: "Laser-induced breakdown spectroscopy: Time-resolved spectrochemical applications," Plasma Chem. Plasma Proc., 1, 281293 (1981).

35) Radziemski, L. J., Loree, T. R., Cremers, D. A. and Hoffman, N. M.: "Time-resolved laser-induced breakdown spectrometry of aerosols," Anal. Chem., 55, 12461252 (1983).

36) Radziemski, L. J., Cremers, D. A. and Loree, T. R. "Detection of beryllium by laser-induced-breakdown spectroscopy," Spectrochim. Acta, 38B, 349-355 (1983).

37) Cremers, D. A. and Radziemski, L. J.: "Detection of chlorine and fluorine in air by laser-induced breakdown spectroscopy," Anal. Chem., 55, 1252-1256 (1983).

38) Amimoto, S. T., Whittier, J. S., Ronkowski, F. G., Valenzuela, P. R., Harper, G. N., Hofland, Jr., R., Trusty, G. L., Cosden, T. H. and Leslie, D. H.: "DF-1aser pulse breakdown induced by maritime aerosols," AIAA Journal, 22, 1108-1114 (1984).

39) Archontake, H. A. and Crouch, S. R.: "Evaluation of an isolated droplet sample introduction system for laserinduced breakdown spectroscopy," Appl. Spectrosc., 42 , 741-746 (1988).

40) Essien, M., Radziemski, L. J. and Sneddon, J.: "Detection of cadmium, lead and zinc in aerosols by laserinduced breakdown spectrometry," J. Anal. Atom. Spectrom., 3, 985-988 (1988).

41) Sneddon, J.: "Direct and near real-time determination of metals in the atmosphere by atomic spectroscopic techniques," Trends Anal. Chem., 7, 222-226 (1988).

42) Casini, M., Harith, M. A., Palleschi, V., Salvetti, A., Singh, D. P. and Vaselli, M.: "Time-resolved LIBS experiment for quantitative determination of pollutant concentrations in air," Laser Part. Beams, 9, 633-639 (1991).

43) Arnold, S. D. and Cremers, D. A.: "Rapid determination of metal particles on air sampling filters using laserinduced breakdown spectroscopy," AIHA Journal, $\mathbf{5 6}$, 1180-1186 (1995).

44) Neuhauser, R. E., Panne, U. and Niessner, R.: "Laserinduced plasma spectroscopy (LIPS): a versatile tool for monitoring heavy metal aerosols," Anal. Chim. Acta, 392, 47-54 (1999).

45) Ottesen, D. K., Wang, J. C. F. and Radziemski, L. J.: "Real-time laser spark spectroscopy of particulate in combustion environments," Appl. Spectrosc., 43, 967976 (1989).

46) Ottesen, D. K., Baxter, L. L., Radziemski, L. J. and Burrows, J. F.: "Laser spark emission spectroscopy for in situ, real-time monitoring of pulverized coal particle composition," Energy \& Fuels, 5, 304-312 (1991).

47) Ng, K. C., Ayala, N. L., Simeonsson, J. B. and Winefordner, J. D.: "Laser-induced plasma atomic emission spectrometry in liquid aerosols," Anal. Chim. Acta, 269 123-128 (1992).

48) Poulain, D. E. and Alexander, D. R.: "Influences on concentration measurements of liquid aerosols by laserinduced breakdown spectroscopy," Appl. Spectrosc., 49, 569-579 (1995).

49) Schechter, I.: "Direct aerosol analysis by time resolved laser plasma spectroscopy - improvement by single shot measurement," Anal. Sci. Tech., 8, 779-786 (1995).

50) Peng, L. W., Flower, W. L., Hencken, K. R., Johnsen, H. A., Renzi, R. F. and French, N. B.: "A laser-based technique for continuously monitoring metal emissins from thermal waste treatment units," Proc. Cont. Qual., 7, 39 49 (1995).

51) Yalcin, S., Crosley, D. R., Smith, G. P. and Faris, G. W.: "Spectroscopic characterization of laser-produced plasmas for in situ toxic metal monitoring," Haz. Waste Haz. Mat., 13, 51-61 (1996).

52) Zhang, H., Singh, J. P., Yueh, F-Y and Cook, R. L.: "Laser-induced breakdown spectra in a coal-fired MHD facility," Appl. Spectrosc., 49, 1617-1623 (1995).

53) Singh, J. P., Yueh, F-Y, Zhang, H. and Cook, R. L.: "Study of laser induced breakdown spectroscopy as a process monitor and control tool for hazardous waste remediation," Proc. Cont. Qual., 10, 247-258 (1997).

54) Hahn, D. W., Flower, W. L. and Hencken, K. R.: "Discrete particle detection and metal emissions monitoring using laser-induced breakdown spectroscoy," Appl. Spectrosc., 51, 1836-1844 (1997).

55) Hahn, D. W.: "Laser-induced breakdown spectroscopy for sizing and elemental analysis of discrete aerosol particles," Appl. Phys. Lett., 72, 2960-2962 (1998).

56) Hain, D. W. and Lunden, M. M.: "Detection and analysis of aerosol particles by laser-induced breakdown spectroscopy," Aerosol Sci. Technol., 33, 30-48 (2000).

57) Lemieux, P. M., Ryan, J. V., French, N. B., Haas, Jr., W. J., Priebe, S. J. and Burns, D. B.: "Results of the September 1997 DOE/EPA demonstration of multimetal continuous emission monitoring technologies, "Waste Management, 18, 385-391 (1998).

58) Neuhauser, R. E., Panne, U., Niessner, R. and Wilbring, $P$.: "On-line monitoring of chromium aerosols in industrial exhaust streams by laser-induced plasma spectroscopy (LIPS)," Fresenius J. Anal. Chem., 364, 720-726 (1999). 


\section{Author's short biography}

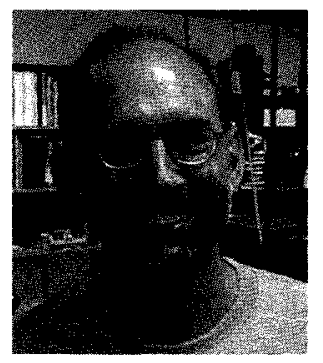

\section{Benjamin W. Smith}

Benjamin W. Smith received his $\mathrm{PhD}$ in analytical chemistry from the University of Florida in 1977. He is presently a Scientist in the Department of Chemistry, University of Florida. His research interests are in laser-based spectrochemical techniques.

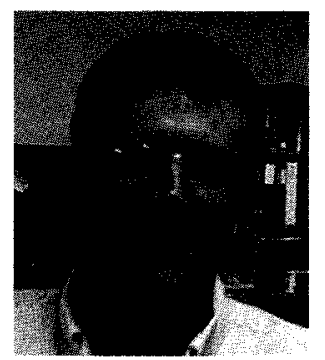

\section{David W. Hahn}

David W. Hahn received his $\mathrm{PhD}$ in mechanical engineering from Louisiana State University in 1992. He was a researcher for the U.S. Food and Drug Administration and Sandia National Laboratories before joining the faculty of the Department of Mechanical Engineering at the University of Florida in 1998. His research interests are in the development and application of laser-based diagnostic techniques.

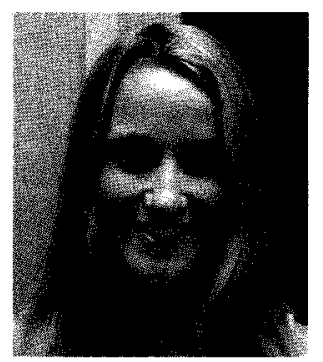

\section{Emily Gibb}

Emily Gibb is a graduate student in the Department of Chemistry, University of Florida. She received her BS in chemistry from the University of Richmond in 1999.

\section{Igor Gornushkin}

Igor Gornushkin received his $\mathrm{PhD}$ in Analytical Chemistry from the University of Florida in 1997. He is presently a postdoctoral scientist in the Department of Chemistry, University of Florida.

\section{James D. Winefordner}

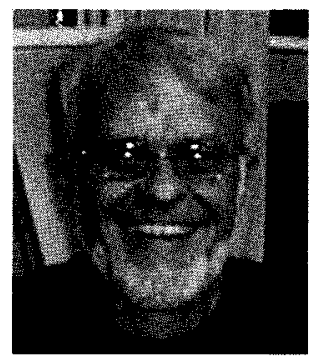

James Winefordner is a Graduate Research Professor in the Department of Chemistry, University of Florida. He received his $\mathrm{PhD}$ in chemistry from the University of Illinois in 1959 and has been a member of the faculty at the University of Florida since that time. He has received, among many awards, the ACS Analytical Division Award in Chemical Instrumentation, the ACS Award in Analytical Chemistry, the Theophilus Redwood Lecture Award and the Royal Society of Chemistry Robert Boyle Medal. He has published over 840 papers in the field of analytical chemistry. 